Renewable Agriculture and

Food Systems

\section{cambridge.org/raf}

\section{Editorial}

Cite this article: Amede T, Whitbread AM (2022). Restoring degraded landscapes and fragile food systems in sub-Saharan Africa: synthesis of best practices. Renewable Agriculture and Food Systems 37, S1-S3. https://doi.org/10.1017/S1742170520000113

Received: 7 January 2020 Revised: 23 January 2020 Accepted: 6 February 2020 First published online: 29 April 2020

Author for correspondence:

Tilahun Amede, E-mail: t.amede@cgiar.org

(c) The Author(s), 2020. This is an Open Access article, distributed under the terms of the Creative Commons Attribution licence (http:// creativecommons.org/licenses/by/4.0/), which permits unrestricted reuse, distribution, and reproduction in any medium, provided the original work is properly cited.

\section{CAMBRIDGE UNIVERSITY PRESS}

\title{
Restoring degraded landscapes and fragile food systems in sub-Saharan Africa: synthesis of best practices
}

\section{Tilahun Amede ${ }^{1}\left(\mathbb{D}\right.$ and Anthony M. Whitbread ${ }^{2}$}

${ }^{1}$ International Crops Research Institute for the Semi-Arid Tropics (ICRISAT), Addis Ababa, Ethiopia and
${ }^{2}$ International Crops Research Institute for the Semi-Arid Tropics (ICRISAT), Patancheru, Telangana, India

Communities in the dryland systems of East Africa regularly suffer from the devastating impacts of climate variability and change, commonly manifested through torrential floods and recurrent droughts. More than $50 \%$ of the natural disasters recorded in East African region have occurred during the past decade affecting nearly 30 million people. For instance, in Ethiopia as recently as 2017, more than 5.6 million people were categorized as being in either crisis or emergency situations and requiring urgent humanitarian assistance (WFP, 2017). Such communities, already struggling to cope with the impacts of unpredictable weather, will face a daunting task in adapting to future climate change unless they adapt improved landscape management practices.

Moreover, climate change is likely to intensify the current challenges of water scarcity in dryland areas and aggravate competition for water within and between communities, affecting communities linked by hydrological flows across watersheds and basins. The major consequences were expressed in terms of increasing water scarcity, drought, torrential flooding and land degradation, catalyzed by deforestation, demographic growth, poor governance, increasing demand for energy and food and other externalities (Amede and Tsegaye, 2016). The spiral of land degradation and water scarcity in these systems has commonly reduced access to feed and food, increasing conflicts, reducing farm incomes, forcing land users to mining of soil nutrients and reducing these once food secure communities to poverty and food insecurity (Amede et al., 2007). This situation is likely to be worsened by global warming and its predicted impacts on seasonal rainfall amounts and distribution, which threaten to exacerbate the climate-induced risk problems already faced by dryland communities, as it was the case in Mali (Zemadim et al., 2020) and Afar (Amede et al., 2020a). This phenomenon is particularly relevant in (agro)pastoral communities, where livelihoods are predominantly at subsistence level and dependent on natural resources (either through livestock keeping, cultivation or harvesting resources from natural habitats) and where there are limited alternative income sources. Although livestock-based systems are sparely populated, the rangeland degradation is so substantial that converting it to a climate resilient system would require significant physical and institutional investment.

This special issue has focused on practical examples drawn from across sub-Saharan Africa which demonstrate the implementation of more climate resilient production systems including watershed management and landscape rehabilitation as the most appropriate means to address the challenges of extreme events and associated food insecurity. Integrated watershed management practices have been employed to achieve the so-called 'triple wins' of adaptation, mitigation and development (German et al., 2007). With its emphasis on improving risk management and strengthening local institutions to support adaptive capacity, improved watershed management is expected to provide foundations for incentivizing and enabling intensification. One of the potential watershed management innovations this special issue treated was flood water management (Amede et al., 2020a), which is a strategy to convert the torrential floods emerging in upstream highlands into productive use through characterizing and capturing flood flows across seasons in highland-lowland settings (Gumma et al., 2020; Amede et al., 2020a).

Floodwaters have been harnessed to grow dryland crops (Getnet et al., 2020; Amede et al., 2020a) and forages (Erkossa, et al., 2020) and could be stored to satisfy increasing water demands during dry spells. Such an approach creates opportunities for multiple use (domestic uses or for human and animal drinking) particularly in drought-prone, pastoral and agropastoral systems. In addition, flood management will quickly recharge ground water for immediate and future uses by dryland communities residing downstream. It has the potential to provide enough water to supplement rainfall and rehabilitate rangelands in pastoral systems.

The papers in this special issue showed that the adaptation capacity of land users to climate change is strongly linked to improved management of land, water and vegetation at farm and landscape scales. The positive impact of soil conservation measures on soil water holding capacity (Zemadim et al., 2020; Erkossa et al., 2020), whereby soil bunds and infiltration trenches 
significantly increased soil moisture content and prolonged the growing period. Integrating improved forages into various crop-livestock and agropastoral systems is also a key strategy for improving water productivity of systems (Getnet et al., 2020) through using underutilized water that could be depleted through non-productive evaporation and run-off. The implementation of various soil and water conservation options showed significant decline in both runoff and soil loss at farm and landscape scales, with significant sediment yield reductions (Yaekob et al., 2020). In fact, the effect of an infiltration trench on soil properties and soil water holding capacity was pronounced when forage grasses, e.g., Chloris gayana were reseeded along with the physical structures (Erkossa et al., 2020). However, the findings of this special issue also indicated that widespread adoption of these technologies is constrained by five major limitations: (i) low levels of attention to pastoral communities; (ii) limited awareness among development partners of climate risk management; (iii) lack of landscape level perspective, (iv) non-consultative, top-down approaches and (v) uncertainty associated with climate impacts especially in degraded landscapes (Amede et al., 2020a).

Moreover, the landscapes in East Africa exhibit extraordinary biophysical, climate and socio-economic variability. For instance, crop response to application of fertilizers is largely governed by the characteristics and topo sequence of landscapes (Amede et al., $2020 b$ ), whereby crop response to inputs is significantly higher in valley bottoms and flatlands compared to hillslopes and degraded uplands (Amede et al., 2011, 2020b; Getnet et al., 2020). Even within a district, micro-variability in culture, hydrology, soils and climate can render techniques found effective on some farms ineffective on others nearby, which calls for adaption strategies reflecting socio-economic realities (Amede and Tsegaye, 2016).

There exists a long term development pathway through which dryland livelihood priorities and associated market expansion drive changes in natural resources management by inducing and enabling farmers to intensify land and water management through investments and innovations (Yaekob et al., 2020; Amede et al., 2020a, 2020b) and by maximizing returns from rehabilitated landscapes using land suitability analysis (et al.,) and remote-sensing tools (Gumma et al., 2020). Integrated investments focusing on soils, water, forest and germplasm would probably give better economic and environmental return in the context of land degradation and climate change. Integrated landscape management, which integrates both decreasing the unproductive water losses (runoff, evaporation, conveyance losses and deep percolation) from a system and increases the water use efficiency of the respective enterprises (Amede and Tsegaye, 2016) will benefit from detailed land suitability analysis, which could guide investment and policy decisions (Kibret et al., 2020). Managing flood at landscape scales also brings unaccompanied benefit of managing run-off, controlling soil erosion and improved vegetative cover (Zemadim et al., 2020; Erkossa et al., 2020). While capturing flood would be an important strategy for developing resilient dryland systems, it has been also observed that flood distribution would create a mosaic system by altering nutrient distribution, soil water holding capacity and crop yield at landscape scales (Getnet et al., 2020). Moreover, there is a need for considering differing landscape management strategies between dryland pastoral systems and crop-livestock systems as the livelihood strategies of these communities hugely vary in terms of institutional settings, collective action modalities, resource management priorities and policy interventions for local action (Amede et al., 2007; Amede and Tsegaye, 2016).
Rehabilitation of degraded landscapes would also require supportive policy, improved facilitation and institutional arrangements at community and higher levels (Amede et al., 2020b), which would facilitate linkages among various actors and organizational systems for scaling-out best practices, developing and enforcing byelaws and increasing investment in the drylands. An interdisciplinary and multi-institutional approach, which recognizes the complexity of landscapes resources governance and use, would provide food, employment and income while assuring the adaptive capacity of dryland communities to climate change. These impacts could be realized if investment in landscape management considers upstream-downstream relationships, put conflict resolution strategies in place and when investment in conservation is linked to productivity and livelihoods.

The highlights of the papers in this special issue are as follows:

Yaekob et al. (2020) used standard erosion plot experiments and hydrological stations to assess the impacts of land use types and land management options on runoff and sediment yield at plot and landscape scales. Their results showed significant decline in both runoff and soil loss at both scales associated with the implementation of various soil and water conservation options. Observed impacts at the landscape scale was significant with sediment yield reduction of $77 \%$.

Zemadim et al. (2020) showed that capturing runoff from agricultural fields in Mali, which often reach $20-40 \%$ of the total annual rainfall, through contour bunding techniques, could reduce drought effects and improve crop productivity. The results showed that soil loss was reduced by $163 \%$.

Erkossa et al. (2020) showed that soil and water conservation using infiltration trenches and C. gayana reseeding together in the dry Ethiopian highlands significantly increased herbage dry matter yield of forages and improved soil chemical properties. The highest biomass yield was obtained when farms with infiltration trenches were reseeded with C. gayana.

Kibret et al. (2020) reported that land management practices such as exclosure-based management are effective interventions to restore ecosystem services. However, lack of tools to support prioritization and more efficient targeting of areas for large-scale exclosure-based interventions remains a challenge. They have presented a multicriteria decision-support tool that would enable and accelerate the planning, implementation and monitoring of ecosystem services restorations and reverse land degradation.

Amede et al. (2020a) showed that devastating consequences of alternated incidence of recurrent drought and flood in East African drylands could be partly minimized by capturing flood emerging from the neighboring highlands to fertilize soils downstream thereby enhance production and productivity of pastoral and agropastoral systems. These positive outcomes could be attributed to proper design of water spreading weirs, joint planning and execution between various stakeholders, particularly clan leaders, identification and availing best-fitting crop and forage varieties and proper land suitability maps for guiding action.

Getnet et al. (2020) assessed the potential effect a flood barrier, water-spreading weirs (WSWs) in Afar, Ethiopia to convert floods emerging from neighboring highlands to a productive use and assessed its effect on production and productivity. WSWs resulted in sediment deposition and soil moisture gradients across fields that also positively affected grain and 
biomass productivity. For instance, average maize grain and biomass productivity in good potential zones was 5 and 15 $\mathrm{t}^{-1}$, respectively. However, there is a need to appreciate variability created by the weirs and mapping within the landscape for targeting appropriate forages and crops.

Gumma et al. (2020) displayed the potential use of near real-time satellite imagery in identifying, assessing and mapping floods for quick decision making, using a case study in Afar, Ethiopia. Through 4 years of monitoring (2015-2018) flood events, a minimum of 142,000 and 172,000 ha of degraded land flooded in the short and long rainy seasons, which could be converted to productive use.

Amede et al. (2020b) showed that targeting and promoting fertilizers in East African highlands, with agricultural landscapes differing across the Catena comprising high elevation hillslopes, midslopes and foot slopes appearing within short distances, requires differing agronomic management and various levels of inputs. With increasing slope, there was a decrease in crop fertilizer response, partly associated with a significant decrease in soil organic carbon, clay content and soil water content.

Acknowledgements. The production of this special issue was supported by BMZ-Germany, through GIZ-SDR Ethiopia and Flagship Project 2, Land and Water Solutions for Sustainable Intensification (LWS) of the CGIAR Research Program Water, Land and Ecosystems (WLE) which is carried out with support from the CGIAR Trust Fund and through bilateral funding agreements. For details visit https://wle.cgiar.org/donors.

\section{References}

Amede T and Tsegaye A (2016) Nurturing agricultural productivity and resilience in drylands of Sub-Saharan Africa. In Farooq M and Siddique KHM (eds), Innovations in Dryland Agriculture. New York, USA: Springer Verlag, pp. 443-466. ISBN: 978-3-319-47927-9.

Amede T, Kassa H, Zeleke G, Shiferaw A, Kismu S and Teshome M (2007) Working with communities and building local institutions for sustainable land management in the Ethiopian highlands. Mountain Research and Development 27, 15-19.

Amede T, Menza M and Awlachew SB (2011) Zai improves nutrient and water productivity in the Ethiopian highlands. Experimental Agriculture 47, 7-20.
Amede T, Dejen A, Legesse G, Tilahun G, Gashaw T, Van den Akker E, Berdel W and Ketter C (2020a) Facilitating transformation of farming systems through flood-based land restoration in drought-prone, agropastoral lowlands of East Africa. Renewable Agriculture and Food Systems (this volume).

Amede T, Gashaw T, Legesse G, Tamene L, Mekonen K, Thorne P and Schultz S (2020) Landscape positions dictating crop fertilizer responses in wheat-based farming systems of East African Highlands. Renewable Agriculture and Food Systems, 1-13. https://doi.org/10.1017/S1742170519000504

Erkossa T, Geleti D, Williams T, Laekemariam F and Haileslassie A (2020) Effect of infiltration trenches and Chloris gayana on biomass production and soil properties of grazing lands in Western Ethiopia. Renewable Agriculture and Food Systems (this volume).

German L, Mansoor H, Alemu G, Mazengia W, Amede T and Stroud A (2007) Participatory integrated watershed management: evolution of concepts and methods in an ecoregional program of the Eastern African highlands. Agricultural Systems 94, 189-204.

Getnet M, Amede T, Tilahun G, Legesse G, Gumma MK, Abebe H, Gashaw T, Ketter C and Akker EV (2020) Water spreading weirs altering flood, nutrient distribution and crop productivity in upstream-downstream settings in dry lowlands of Afar, Ethiopia. Renewable Agriculture and Food Systems, 1-11.

Gumma M, Amede T, Getnet M, Pinjarla B, Panjala P, Legesse G, Tilahun G, Van den Akker E, Berdel W, Ketter C, Siambi M and Anthony W (2020) Assessing potential locations for flood-based farming using satellite imagery: a case study in Afar region, Ethiopia. Renewable Agriculture and Food Systems (this volume).

Kibret KS, Haileslassie A, Mekuria Bori W and Schmitter P (2020) Multicriteria decision-support system to assess the potential of exclosurebased conservation in Ethiopia. Renewable Agriculture and Food Systems, 1-15. https://doi.org/10.1017/S1742170520000034

WFP (World Food Programme) (2017) WFP East and Central Africa Horn of Africa Drought Crisis Situation Report \#3, 15. http://reliefweb.int/report/ somalia/wfp-east-central-africa-horn-africa-drought-crisis-situation-report3-15-march-2017 (Accessed 22 December 2019).

Yaekob T, Tamene L, Gebrehiwot S, Syoum S, Adimassu Z, Woldearegay K, Mekonen K, Amede T, Abera W, Recha J and Solomon D (2020) Assessing the impacts of different land uses and soil and water conservation interventions on runoff and sediment yield at different scales in the central highlands of Ethiopia. Renewable Agriculture and Food Systems (this volume).

Zemadim B, Traore K, Tabo R and Whitbread A (2020) Agricultural intensification and erosion control through land and water management practices in semiarid Mali. Renewable Agriculture and Food Systems (this volume). 